Social Work/Maatskaplike Werk Vol 57 No 1; Issue 8

http://socialwork.journals.ac.za/pub doi:http://dx.doi.org/10.15270/52-2-810

YOUTHS IN GANGS ON THE CAPE FLATS: IF NOT IN GANGS, THEN WHAT?

Marichen van der Westhuizen, Sibulelo Gawulayo

Youths in gangs on the Cape Flats have been reported to be a major and ongoing concern. It is therefore necessary to explore what prompts youths not to join gangs, or to exit gangs. This article is based on a secondary analysis of data that focused on the perceptions of youths in the Cape Flats of the reasons for youths joining gangs. The findings point to individual, family and environmental contributing influences. The discussion is concluded with some recommendations for interventions aimed at providing youths with alternatives to prevent them from joining gangs, or to assist them to exit gangs.

Keywords: Cape Flats, environmental influences, family influences, gangs, youth, individual influences 



\title{
YOUTHS IN GANGS ON THE CAPE FLATS: IF NOT IN GANGS, THEN WHAT?
}

\section{Marichen van der Westhuizen, Sibulelo Gawulayo}

\author{
Professor Marichen van der Westhuizen, Department of Social Work, University of the Western \\ Cape, Bellville, South Africa.
}

Mr Sibulelo Gawulayo, Department of Social Work, University of the Western Cape, Bellville, South Africa.

Keywords: Cape Flats, environmental influences, family influences, gangs, youth, individual influences

\section{INTRODUCTION}

Gangs are social groups within geographical territories that use symbols, verbal and non-verbal communication to express their belonging to the group, and resort to crime to exercise power and control over the territory in which they operate (De Wet, 2016; Cooper \& Ward, 2012). They are formed to claim control over a specific market, such as illegal substances, in a specific territory. Activities are organised through leadership structures and an internal organisation of roles and responsibilities for gang members. Criteria for the functioning of gangs in general include a command structure, exerting power over a territory and its inhabitants and its resources, and use of armed violence. The above criteria are also applicable to youth gangs (Cooper \& Ward, 2012).

This discussion will focus on the Cape Flats, where violent gang-related crimes are a major cause of concern. In the middle of 2019 the South African National Defence Force moved in to guard the residents against the high levels of gang-related violence. In order to understand gangsterism in this area, one needs to consider the history of the Cape Flats. During the forced removal of families from their homes in the old Cape Town neighbourhoods to the Cape Flats, the sense of community and the dignity of people were deeply affected (Pinnock, 2019). This contributed to a general sense of powerlessness (Bowers Du Toit, 2014; Kahn, 2013). The Cape Flats' history of being a wasteland that was used to forcefully relocate families during the apartheid era has been documented as one of the roots of gangsterism in this area. The areas that had to be relocated were known for their "skollies or street gangs, and these gangs became violent territorial gangs once they were moved to this are of "sheer misery", which is the Cape Flats (Bowers Du Toit, 2014:2). It has resulted in youths today being exposed to a gang culture that has been established over decades. Furthermore, the sense of powerlessness in the community remained even after apartheid ended, and is supported by high levels of youth unemployment (Pinnock, 2019). In addressing the question of youths facing the prospect of access to power and financial means, and being protected by a gang, one has to ask what the alternative could be for the youths living in the Cape Flats.

A background discussion will describe the rationale for this article and the research findings, followed by a summary of the research methodology. The findings will be presented together with confirmation from the literature on the topic. The discussion will be concluded with some recommendations for providing vulnerable youths with alternatives to prevent youth gang affiliation, and to support youth in gangs to exit gangs.

\section{BACKGROUND AND RATIONAL}

Cape Town has been described as the murder capital of the world. This unfortunate label is supported by statistics, e.g. the 2302 murders that occurred in the city during the first six months of 2019 , representing a murder rate of 100/100 000, compared to the average rate of 33/100 000 in South Africa, and 6/100 000 in the world (FW de Klerk Foundation, 2019). Gang-related murders on the Cape Flats in Cape Town provides one explanation for the high murder rate in Cape Town. It is estimated that gang membership in this area ranges between 80000 and 100000 members in approximately 130 gangs. These gangs contribute up to $70 \%$ of all crimes committed within the area (Van der Linde, 2018). 
Gangs and violence on the Cape Flats are viewed as two sides of the same coin. This perception is supported by reports of incidents such as the 17 killings of innocent bystanders in 16 days in 2014 (Bowers du Toit, 2014), 10 people, among whom two children, killed in one weekend in December 2018 (Le Magidi, 2018), 13 people killed in July 2019, including six women and three youths (FW de Klerk Foundation, 2019), and the gunning down of a 30-year-old pregnant women and a 7-year-old girl during February 2020 (Head, 2020; Petersen, 2020). Similarly, youths' association with gangs in this area also includes violent behaviour (cf. Choe, Zimmerman \& Devnarain, 2012). An analysis of 41 media articles dating back to 1998 on school violence in the Western Cape linked violence in schools to gang affiliation. As one explanation, a study among reformed gangsters indicated easy access to weapons and carrying some sort of weapon as normative in the Cape Flats (De Wet, 2016).

Exploring possible contributing factors, the South African Police Service (2019) reports that gang-related violence on the Cape Flats is often related to clashes between residents and gang members, or competition between gangs related to the distribution of weapons and/or illegal substances (cf. Head, 2020; Kinnes, 2017). In support of this viewpoint, the Western Cape Department of Community Safety (2018) acknowledged that police services on the Cape Flats face major challenges with substance abuse and gangs, and added that police officials are being controlled by gangs and corrupt politicians who have control of the drug trade in specific geographical areas.

De Wet (2016) reports that incidents of children as young as 9 years old enter gangs on the Cape Flats. Although youth in gangs do not only include males or vulnerable youths, the author reports that gangs on the Cape Flats mainly target boys and focus on their need for recognition. Furthermore, youth unemployment does not only have economic consequences, but its social implications should not be underestimated. Youths with no hope for further education and access to employment might view gang membership as the only way to secure a future (Bernstein, 2017). This aligns with Bandura's social learning theory that explains social behaviour as acquired through observation and imitating others (Johnson, 2014). Peer pressure has been identified as another key reason for male youth joining gangs in the Western Cape (De Lannoy, 2018).

Confirming these contributing factors to youths joining gangs, Collins (2013:34) describes "how to create a violent society" and lists the following factors: normalisation of violent reactions to stress and conflict (cf. De Lannoy, 2018), witnessing and being a victim of violence, a lack of emotional support to vulnerable youths, exposure to trauma, and no access to services to support youths with the skills to manage trauma and to resolve conflict in a non-violent manner (cf. Department of Social Development, 2012). Sauls (2014:13) reports that youths in the Western Cape are "constantly confronted with issues of safety and violence", and have to deal with gang affiliations in schools, which is also linked to substance abuse. De Wet (2016) identified poverty, unemployment, rural-urban drift, access to weapons, and a historical legacy of territorial violence as contributing factors to youths entering gangs. In line with international trends, youths on the Cape Flats find gangs attractive because of the sense of belonging membership provides, the recognition youth experience within the gangs, and a way to survive poverty and violence in their communities (De Lannoy, 2018; De Wet, 2016). One aspect that came to the fore in a study conducted by the Western Cape Department of Social Development (2012) was that exposure to gang-related activities impacts on the development of identity. Youths exposed to gangs come to believe that belonging to a gang serves an important purpose to develop an identity through the gang's identity. Gang affiliation provides them with safety, a sense of social inclusion and belonging, financial means and a sense of masculinity (Sauls, 2014).

The above descriptions indicate that the same causal factors have been identified by a number of studies in different contexts over a period of time. Sadly, studies conducted between 2012 and 2018 highlight the fact that youths in gangs remains a social phenomenon, indicating that efforts to address this have not been effective. The need for this present discussion is based on, among other things, De Lannoy's (2018) conclusion that existing programmes to address youth in gangs do not connect with the real needs of children and youths. 
The research problem that informed this research was derived from a variety of studies that have explored the reasons behind youth gang involvement. However, interventions appear to have little impact as youths on the Cape Flats continue to join gangs. A need to explore alternatives when interpreting the reasons behind youths joining gangs therefore informed this discussion. With the above understanding of how gangs in communities affect youths, how this can lead to gang association, and recognising the lack of access to services and opportunities among vulnerable youths, this article explores the following question: If vulnerable youths are not to affiliate with gangs, what are their alternatives? The purpose of this article is therefore to explore alternative options for youths to be included in intervention and preventative strategies in areas where they are vulnerable to gangs.

\section{Theoretical framework}

Already in 2013 the Western Cape Department of Social Development (2013:2) had launched a Youth Development Strategy to "create more support, opportunities and services for all young people to better engage with their environment (external and internal) and successful transition into responsible, independent, productive, healthy and stable adults". This requires a multi-systems approach. Van der Merwe, Dawes and Ward (2012) postulate that risk factors can also can be included in preventative and intervention strategies. These authors point to an ecological understanding of youth violence and association with gangs. According to the ecological systems theory, interventions aimed at youth in gangs, as well as the prevention of this occurring, could be addressed effectively when the different systems in youths' lives are included in interventions (Van der Merwe, et al. 2012). Ward, Van der Merwe and Dawes (2012) refer to this model as a multilevel model of intervention, focusing on 1) individual factors, 2) everyday contexts that include family and peers, 3) community contexts, and 4) cultural, economic, social and political contexts. This description was used to guide the study that informed this discussion.

\section{METHODOLOGY}

This discussion forms part of a research project that entailed three different studies exploring and describing youths in gangs on the Cape Flats from the perspectives of the youths, parents/guardians and service providers. The primary data were obtained as part of undergraduate studies in social research in the Department of Social Work at the University of the Western Cape. This article is based on an analysis of the perceptions of the youths. The primary study included a total of 395 semi-structured interviews conducted by students with youths on the Cape Flats. Each student compiled a research report representing the data they collected.

For the purpose of this article, a secondary data analysis was used to analyse the findings derived from the primary study. This is a valuable tool when doing research among vulnerable groups, so as not to over-expose participants to research (Devlin, 2018). George, Ferguson and Pearce (2014) assert that secondary analyses can be viewed as a way to support evidence-based practice in that they can be used to bridge the gap between research results and their transference into practice.

A qualitative approach was followed to obtain the primary data that informed this discussion. This approach also informed the secondary analysis of the findings, because the focus remained on describing and interpreting the perceptions of the people affected by youths in gangs on the Cape Flats. The aim was to develop a collective story through an interpretive framework that is embedded in the social context (Lapan, Quartaroli \& Riemer, 2012). A phenomenological research design was used to guide the choices regarding the identification of sources and data to be included and the method of analysis (Koopman, 2015). The phenomenological design supported the inductive qualitative research approach, as it contributes to developing new meanings of how people understand their lived experiences, and how they structure their understanding of them (Bliss, 2016).

All the research reports were included as possible documents to be analysed (Bryman, 2016). The authors started with those reports that received the highest marks during the assessments of the students' work, based on the assumption that the quality of these reports will be reflected in the quality of the findings. 
The analyses of the reports continued until data saturation was reached, followed by one more analysis to ensure that no more new data emerged. A total of 12 reports were included.

Ritchie, Lewis, Nicholls and Ormston (2014) argue that one has to consider whether it is necessary to obtain new or more data and information regarding a research topic, or whether existing data and information should be explored and analysed to make sense of what we already know. A meta-analysis is referred to as "an analysis of analyses" (Devlin, 2018:47). Jain, Sharma and Singh (2012) explain that, through a meta-analysis process, the primary data of a variety of sources are transformed into new information and insights. This description aligns with the phenomenological nature of this discussion. Jain et al. (2012) note that meta-analyses of qualitative data should follow a scientifically sound process to ensure the validity of the final narrative related to the findings. The secondary analysis in this study followed a process of meta-analysis, described by George et al. (2014) as entailing the following steps:

- Identify recent primary sources of data that address a specific phenomenon of interest. All the research reports were included in the unit of analysis;

- Select studies that will be most relevant for the purpose of the analysis. The authors started with the reports that were determined to be of the highest quality, and continued until data saturation was reached;

- Follow a systematic and scientifically sound process to analyse the findings of the primary data sources. Tesch's framework for qualitative data analysis, as discussed by Creswell (2009), was employed;

- Identify and describe the main themes, sub-themes and categories. After the data were analysed, a final decision was made regarding those themes, sub-themes and categories that could best describe the perspectives of youths on youth gang affiliation, and alternatives for youths living on the Cape Flats.

- Interpret the findings of the secondary analysis. Based on the themes, sub-themes and categories, conclusions were drawn and disseminated in this discussion paper.

The criteria for data verification were based on a description by Schurink, Fouché and De Vos (2011). Credibility was ensured through a formalised and scientifically acknowledged process of data analysis and triangulation of sources of data. Peer debriefing involved working in a team, which meant that reflexivity formed part of the analysis so as to ensure that the interpretations were based on what was obtained from the primary data and not influenced by personal perspectives and experiences. Transferability and dependability were addressed through the phenomenological nature of the study, which meant that interpretations were focused on the specific context of the Cape Flats. The authors do not claim that these findings will be consistent with the perspectives of other people or groups in other contexts. The clear description of the methodology used to do the secondary analyses, as well as the quality of the primary data, contributed to dependability as the larger project could be repeated in other areas. The contextualised findings could then be compared. Conformability involved the description of the primary data in terms of the direct and verbatim descriptions of the participants, which was also used in the secondary analyses. The use of the same method of data analysis for both the primary and secondary data analyses further supported the findings.

Tryphany (2013) advises that, when the primary data are free of any form of personal or identification information, the secondary analysis does not need renewed ethical consent. On the contrary, this means that confidentiality is already ensured. In this study the original study obtained ethical clearance from the relevant authorities in the University and the Department of Education, and participants were informed that the data would be described in a formal research report with the purpose of disseminating the findings. It should also be noted that the secondary analysis did not entail the use of the original transcripts where the personal information of the participants could be exposed. The authors were involved in the process of obtaining the primary data as supervisors of the research project, and the 
contribution of the other researchers in this project is acknowledged. The students were also informed from the start that the research reports that they compiled will be disseminated in different formats.

\section{FINDINGS}

Three themes emanated from the secondary data analysis, namely personal, family and environmental factors that prompt youths to join gangs on the Cape Flats. These findings are in line with the ecological systems theory, which is concerned with understanding the factors that influence the development of youths within their respective environments (Peppler, 2017).

\section{Theme 1: Personal factors}

Personal factors refer to internal factors that contribute to the wellbeing and functioning of an individual (Grotkamp, Cibis, Nüchtern, Von Mittelstaedt \& Seger, 2012). In this analysis, the following personal factors that need to be acknowledged when looking for alternatives to youth gang involvement were identified: low self-esteem, seeking approval from peers, and the benefits of being part of a gang.

\section{Sub-theme 1.1: Low self-esteem}

Self-esteem is evaluative of the self (Moksnes \& Reidunsdatter, 2019). A low self-esteem leads to a need to belong and be accepted by others (Orth \& Robins, 2013). During adolescence, the individual's selfesteem becomes vulnerable to several internal and external impacts (Abdel-Khalek, 2017; Orth \& Robins 2013). The findings show that low-self-esteem is one of the primary reasons for youths joining gangs, motivated by an assumption of enhanced status when associated with a specific group of people:

I feel that a major cause of gangsterism is that people have low self-esteem and do not feel recognised... uhm therefore they turn to gangsterism so that people can respect them and so that they can feel a sense of belonging that they lack. This makes them feel that they can stand up for themselves... you know... to feel protected. (Participant 1 in Report 10)

Furthermore, the fear of being perceived as different puts pressure on youths to conform to what is happening around them. Aligning themselves with specific gangs gave the participating youths on the Cape Flats a feeling of prestige, status and respect:

If we are together as a group of five, for example, and there is maybe one of us who is not part of a gang group, that person is most likely to feel the need to join a group, because they do not want to stand out. (Participant 1 in Report 1)

The link between the micro and mezzo system is highlighted as the statements above show that a low selfesteem, on a micro level of functioning, stems from a lack of respect from peers, as well as a fear of being targeted if the youth do not conform to the norms of gangs in the area where they live. This, then, serves as a motivation to change behaviour to be recognised and respected among peers and in the environment in which they function, affecting their overall development (Beyers, 2018; Peppler, 2017). De Wet (2016) and Sauls (2014) identified the school environment as a place on the Cape Flats where the pressure to join a gang is experienced. A school environment that is harmful places the development of youths under threat, especially those with low self-esteem and lack of self-understanding (Blazevic, 2016). A low self-esteem therefore also leads to behaviour that is aimed at obtaining approval from peers.

\section{Sub-theme 1.2: Seeking approval from peers}

You want to be part of gangsterism and um you get peer pressure ... and then umm you see people, you see the gangsters with guns and you want to be part of it, because you see how cool it looks and do things like that. (Participant 3 in Report 2)

During adolescence, young people attempt to understand themselves in relation to their peers (Bayat, Louw \& Rena, 2014). For some adolescents this creates a culture where self-esteem is dependent on the approval of and acceptance of others. Findings reveal that peer pressure is one of the central factors that inform youths' decisions to join gangs: 
The main cause is peer pressure. There are friends that want to impress the big gangsters or get money from them. (Participant 1 in Report 6)

Cooper and Ward (2012) refer to individual factors contributing to gang affiliation in terms of pressure to conform to the behaviour and rules of the perceived influential people in these gangs in the youth's environment.

The findings highlight an interplay between the self-esteem and the need for approval and acceptance from peers (Rich \& Roman, 2019). In order for the youths on the Cape Flats to be accepted or regarded as part of the group, they have to participate in the tasks initiated by the gangs they join. This also relates to a need to be accepted and to fit into their social context. A participant described this aspect as follows:

I think they want to be seen as cool and want to gain respect from others in their community. (Participant 5 in Report 12)

On the Cape Flats gangs are viewed as normative and there is therefore a risk that youths would join gangs to be able to fit into their environment (De Lannoy, 2018; Sauls, 2014). This then requires youths to engage in criminal activities. This need to fit in often stems from a need to belong, according to the youths who participated in the research.

Gangsters see themselves as kind of families, you see. So if you come from a home that is broken up you will always look for somewhere to fit in. So they accept you and it's easy to find... (Participant 3 in Report 3)

The ecological systems theory identifies family and peers as the systems that provide youths with a sense of belonging. If these systems fail them, gangs can step in and provide them with a place where they can feel acknowledged and where they fit in (De Lannoy, 2018).

\section{Sub-theme 1.3: Benefits of being part of a gang}

The Cape Flats is characterised by poverty and unemployment, leaving the residents with a sense of powerlessness (Western Cape Department of Community Safety, 2018; Bowers Du Toit, 2014). The City of Cape Town also acknowledges that, in order to provide youths with alternatives to gang affiliation, economic opportunities need to be created (Kesson, Morgan \& Green, 2018). The findings confirm that poverty contributes to youths' perception of the benefits of belonging to a gang:

School-going youth join gangs, because they are able to get the money that they can use on themselves. (Participant 3 in Report 4)

Gangs 'advertise' themselves in this context as being successful:

The majority of gang members walk around with different and expensive things, such as clothing, cell phones and cars. (Participant 2 in Report 4)

In the light of the ecological systems theory (Ward et al., 2012), the cultural and socio-economic context of the Cape Flats therefore contributes to the youths' perceptions of the benefits of belonging to a gang.

\section{Theme 2: Family factors}

The findings revealed a number of challenges that youths on the Cape Flats experience related to their families, namely a lack of sense of belonging; lack of love, acceptance and support; child-headed households; dysfunctional or absent parental/guardian supervision; and lastly, exposure to violence at home.

\section{Sub-theme 2.1: Lack of sense of belonging}

Many youth are joining gang groups, because their parents do not give them enough love and attention...(Participant 5 in Report 6)

Healthy parent-child relationships have to do with, among other things, creating a space where youths feel they are wanted and that they belong (Rich \& Roman, 2019:391). Blazevic (2016) asserts that youths 
who have close relationships with parents tend to possess or develop a strong sense of self-respect and self-confidence, perform better in school, develop healthy social relationships, and display a high level of independence and emotional maturation. In contrast, the participants in the studies that informed this discussion reported that a lack a sense of belonging leads youths to joining gangs:

I think ... for example, if your parents don't care about you, and you find another home where parents are on drugs...that will mess you up and then it is easy to just join a gang. (Participant 4 in Report 10)

Another participant reported that a sense of belonging is created by the group activities:

Members of the group always do things together. (Participant 1 in Report 1)

Attachment in the parent-child relationship is an important mechanism that fosters positive development supports skills to build positive relationships with peers (Gould \& Ward, 2015; Rich \& Roman, 2019). Rich and Roman (2019) argue that insecure attachments influence youths' ability to deal with peer pressure and to adapt to rules in society. The participants' responses above support this argument in that the youths living in the Cape Flats explained that a lack of parental care, guidance and involvement contributes to their finding a 'home' with gangs.

\section{Sub-theme 2.2: Lack of affection, acceptance and support}

The lack of a sense of belonging leads to youths not experiencing affection, acceptance and support in their microsystem (Peter, Peter \& Catapan, 2015). Lachman, Sherr, Cluver, Ward, Hutchings and Gardner (2016) refer to positive parenting that is necessary for youths to develop a positive self-esteem, to deal with peer pressure and other environmental influences, and to develop a positive social identity. The responses of the participating youths linked parental acknowledgment, affection, acceptance and support with youths' decision to join gangs. A participant explains that a youth with low self-esteem caused by family circumstances can become susceptible to joining a gang:

I am not a gangster, but from personal experiences, my mum focus never used to...like when I used to come home with good results...she just used to focus on other things that I need to do better at. She would never praise me... and this made me feel isolated. Now, what about weaker people than me? I think this lack of love drives people to turn to gangs. (Participant 2 in Report 10)

Another participant explained that a lack of support and care in the home is the main cause for youths seeking another 'home' through gang membership:

Uhm ... out of all causes, I think lack of parents' love, and also a family who is disorganised, lead people to gangsterism, because they do not have support at home and the gang members make them feel loved and needed. Uhm ... I think people cannot just become gangsters, they do not have a support structure nor love from family. (Participant 1 in Report 10)

These statements are supported by Rodrigo, Byrne and Rodríguez (2013), who explain that uninvolved parenting is a form of neglect that could cause youths to seek acceptance and recognition elsewhere, in this case gang membership. Similarly, Van der Westhuizen (2015) identified a need for acceptance and recognition as a key social need among vulnerable youths. Without acceptance and recognition from parents, youths will turn to groups where they will be able to satisfy this social need.

\section{Sub-theme 2.3: Child-headed households}

Pillay (2016) describes child-headed households (CHH) as those where biological parents, a legal guardian or primary caregiver has a terminal illness or had passed away, and there are no family members who are available to provide suitable care for the children. This subsequently results in the child having to take on caregiving roles and to support siblings. The participating youths on the Cape Flats identified a lack of parents as a cause of youths joining gangs: 
They live in homes where parents are not there, and they must find a way to look after themselves and maybe their brothers and sisters. (Participant 3 Report 3)

Maybe someone at home lives alone, maybe parents passed away. Maybe that person lost his/her parents while still young. (Participant 3 in Report 1)

They not only referred to parents/guardians not being present, but also to parents not being able to care for the family's material needs:

Another thing maybe; at home they are poor and they depend on him in order for them to eat. (Participant 3 in Report 1)

The National Plan of Action for Children in South Africa (Department for Women, Children and People with Disabilities, 2012-2017:77) is aimed at ensuring "that the rights of children living in child-headed households are protected". The findings in this study point to the fact that children in CHH continue to be vulnerable.

\section{Sub-theme 2.4: Dysfunctional families and/or lack of parental/guardian supervision}

The decision to join gangs is also, according to the participating youths, caused by family dysfunction and/or a lack of supervision and guidance.

The main cause is families that are not taking care of their children. (Participant 2 in Report 6)

A participant specifically referred to a lack of structure in the family as a causal factor for gang involvement:

Youth who have behavioural problems are influenced by parents who do not provide structure and support system to their children. This often results in youth joining gang to their unfulfilled needs. (Participant 5 in Report 4)

Another participant explained that family problems become the norm for youths:

...children will think that is the right way to live. (Participant 4 in Report 10)

Bayat et al. (2014) confirm such statements and argue that a lack of parental guidance and family structure results in an inability to make positive decisions, and youths being susceptible to negative peer pressure, which includes joining gangs.

\section{Sub-theme 2.5: Exposure to domestic violence}

The findings point to the fact that exposure to violence in the family system often leads to violent behaviour among adolescents (cf. Gould \& Ward, 2015).

The majority of young people in the community come from violent, poor and abusive backgrounds. Youth see violence in their homes every day at the hands of the mothers, father and even siblings. (Participant 3 in Report 4)

Participants linked substance abuse to domestic violence and the neglect of children, and added that this influences the behaviour of youths:

Sometime parents do not take care of their children, and are violent. Or sometimes they do drugs themselves, and you feel like; what is the use of you not to trying out drugs as well. (Participant 4 in Report 6)

Participants in a study in the Western Cape that focused on the impact of domestic violence on young adults highlighted that exposure to domestic violence during childhood leads to youths 1) resorting to violent acts to deal with their anger, and 2) developing a sense of belonging in a group where violence is acceptable (Warnick, Van der Westhuizen \& Alpaslan, 2019).

The gangs on the Cape Flats are known for their violence, providing youths who adopt violent behaviours with a social context in which this behaviour is further supported and even nurtured (cf. Pinnock, 2019). 
Violence in the family and neighbourhood can therefore lead to youths being drawn to violent groups in the macro environment.

\section{Theme 3: Environmental factors}

According to the ecological systems theory, the environment in which youths grow up is the macro system that includes a set of beliefs, values, norms, culture, religious systems and the socio-economic organisation of the society (Peppler, 2017). The microsystem can influence interactions with the mezzo and macro systems, while the macro system can influence the interaction with the mezzo and microsystems (Peppler, 2017). Cooper and Ward (2012) refer to the community context that can contribute to youth gang affiliation as tolerance of criminal behaviour, violence and substance abuse; poverty and unemployment or a lack of options; and gangs who are perceived as the ultimate power structure in the community. The authors also assert that societal factors such as a high level of youth unemployment, a lack of access to support services, corrupt state structures, and violence perceived as the best way to deal with stress and conflict as further contributing factors. The participating youths identified a lack of economic resources, crime and a need to protect themselves, as well as the influence of substance abuse, as key aspects in their environment that contribute to youths becoming susceptible to joining gangs.

\section{Sub-theme 3.1: Lack of economic resources}

The rate of unemployment in South Africa has risen to 29\% (Statistics South Africa, 2019). Bayat et al. (2014) stress that youth unemployment is a serious social issue that leaves youths vulnerable to being attracted to the benefits of gang affiliation. This has been confirmed by a variety of studies over the past decade (cf. Bernstein, 2017; TBowers Du Toit, 2014; Sauls, 2014). The findings again confirm the impact of poverty and unemployment on youth behaviour. One participant acknowledged that crime becomes a way to deal with poverty, but added that youths selling illegal substances should rather return to school.

People who are not working sell drugs and they should stop what they are doing by going back to school so that they can have a job to support themselves and their families. (Participant 5 in Report 8)

Another participant, however, argued that the reality of unemployment serves as a motivation to become involved in gang-related activities:

\section{Most people who are involved in gangsterism are unemployed. (Participant 2 in Report 8)}

The findings highlight that youth join gangs for economic gain as way to escape unemployment and poverty. The Cape Flats is an impoverished area and has high levels of unemployment (Davids, 2019). It is evident that when young people are discouraged by the lack of employment and entrepreneurial opportunities, they find it easy to commit gang-related crimes for economic gain. The interrelatedness of poverty and unemployment and family dysfunction has further been highlighted in the literature (Davids, 2019). In a study conducted by Rich and Roman (2018), poverty has been identified as a factor that has an influence on parenting and therefore on the development of children. Sherr et al. (2017) agree that parents faced with poverty and unemployment are occupied with the struggle to provide for their children, resulting in a lack of time to establish and sustain healthy relationships with their children.

\section{Sub-theme 3.2: Crime and protection of the self}

Youths sometimes do not see another option but to join a gang to protect themselves:

Some of the young people join a gang after being bullied at school so that their gang members can fight for them. And bullying also happens in the community. (Participant 2 in Report 5)

Pillay (2016) also found that youths who do not feel safe in their environment, either the school or the neighbourhood they live in, may find joining a gang as the only way to protect themselves. A participant explained that gangs often pressure youths to engage in gang-related activities and that they are being targeted when they refuse to participate, which causes a major risk for the youths in the Cape Flats: 
If a person within a group refuses maybe to steal or participate in a gang fight, that group comes back to that person to either beat or kill them, because they feel betrayed by that person. (Participant 1 in Report 1)

Youths then make a conscious decision to join the gang to protect themselves (cf. Sauls, 2014).

Similarly, in a comparative analysis of gangsterism in the Western Cape, Petrus and Kinnes (2019) found that gangs threaten the safety and security of community members they operate in. Therefore, the above consciously made decision is in reality responding to a form of coercion. Gang members use different forms of violence to lure youths to join gangs involuntary. Bowers Du Toit (2014) argues that gang leaders also use violence to keep members loyal to the gang to maintain its existence and functionality.

\section{Sub-theme 3.3: The influence of substance abuse}

According to Wijnberg (2012), gang members use substances before committing criminal activities to suppress the guilt and shame. The participants in this present study confirmed this and explained that substance abuse often leads to youths joining gangs to access substances:

In X (specific area) drugs are sold everywhere in the community and young people often join gangs to have access to drugs. (Participant 1 in Report 4)

A participant further explained that gang members use substances to lure youths to gang affiliation:

And the other thing; we see those who are instituting gangsterism here at school, they even sell drugs here at school and that makes other learners to use drugs. (Participant 3 in Report 1)

The latter statement is supported by Magidi, Schenck and Erasmus(2016), who observed how gangs wait outside school gates to engage with youths after school, offer them substances or intimidate them. The above findings informed the concluding recommendations of this discussion.

\section{CONCLUDING RECOMMENDATIONS}

The findings above confirmed the results of a variety of other studies related to the topic of youths in gangs over a period of time. Youths joining gangs on the Cape Flats remains a major concern. In order to provide youths with opportunities to explore options to develop resilience, not to join gangs, or to exit gangs, the concluding comments will focus on the ecological systems in their lives.

\section{Individual factors}

The interaction between individual factors that support gang affiliation and the environment in which youths function should be considered when interventions are planned. Van der Westhuizen (2015), also focusing on youths in the Western Cape, identified environments where substance abuse, violence and crime are rife as a crucial influence on adolescents' ability to develop a positive sense of self, to find a positive and supportive peer group, and to develop a future vision. The findings in this article provide a picture of low self-esteem that stems from feelings of not belonging within the family system, which leads to behaviour to gain approval from peers in an effort to fit in and to experience a sense of belonging. In a community where poverty and unemployment lead to substance abuse, crime and violence, adolescents will be lured to gangsterism as a way to escape poverty and to survive in a violent community.

Life-skills programmes in such circumstances, without active solutions for the socio-economic context, can support the development of resilience, but a lack of ongoing social support and positive role models to encourage the integration of life skills into everyday living undermine any successful outcomes of such programmes. Long-term exposure to violence and crime, and a lack of a sense of security during childhood, cannot be 'fixed' with short-term interventions on mezzo or macro levels of functioning. The trauma experienced by youths and their families on the Cape Flats requires therapeutic input where the impact of trauma can be dealt with and where healing can take place. 


\section{Everyday contexts that include family and peers}

The individual factors above are often influenced by the everyday contexts of youths on the Cape Flats. A lack of a sense of belonging and being loved and accepted, along with a lack of support in their families, leads youths to become dependent on this in peer groups. In a context where gangs are looking for new members, these young people become particularly vulnerable to finding a 'home' in the gang. In order to address the social phenomenon of youths in gangs, they need a place where they feel that they are accepted, where they are loved, and where they receive support and encouragement. In addition, the influence of substance abuse and gangsterism has a serious influence on families, and also on influencing youths to abuse substances, engage in violent behaviour and to join gangs (cf. Davids, Londt \& Wilson, 2015).

In order to provide youths with an alternative to gangs, family systems need to be strengthened and vulnerable youths must be provided with environments where they can experience a sense of belonging, love, acceptance and support. Specific consideration should be given to the treatment of substance abuse, including aftercare, and to the domestic violence that is often related to substance abuse (Warnick et al., 2019). This is also connected with the socio-economic circumstances of the youths and their families. Where poverty and ongoing unemployment leave families powerless, youths will be pressured to find ways to escape the impact of this situation.

\section{Community contexts}

Unemployment and a lack of access to economic resources, crime, a need to protect themselves in a violent community, and the influence of substance abuse have been identified as causal factors in youths joining gangs through the secondary analysis described here. Sadly, these factors have been indicated by a variety of studies over a number of years (cf. De Lannoy, 2018; Bernstein, 2017; De Wet, 2016; Bowers Du Toit, 2014; Sauls, 2014; Choe et al., 2012; Department of Social Development, 2012).

As mentioned already, interventions focusing on individual, family and peer factors alone cannot effectively provide youths with alternatives to joining gangs. Effective interventions will require the development of the Cape Flats community, providing them with employment opportunities, rehabilitation and aftercare options to deal with substance abuse, addressing the normalisation of violent behaviours, and providing community structures such as sport and arts facilities, all of which encourage healthy living.

\section{Cultural, economic, social and political contexts}

The culture of gangs and their power in the Cape Flats must be addressed by providing youths with examples of other means to achieve success. The findings emphasise the interrelatedness of individual, everyday life and community contexts. As such, interventions within the different systems must be interrelated and connected to each other. This needs the political will to support the development of the community, the provision of employment opportunities, the provision of the necessary social and economic services, and the encouragement of interventions to develop a positive culture that is based on hope for a better future.

In conclusion, the analysis of primary data and the descriptions in other related literature emphasise the importance of taking the historical influence on the socio-economic situation on the Cape Flats into consideration when attempting to address the social phenomenon of youths in gangs. It is also important to understand that youths will need to be involved in the identification, planning and implementation of interventions aimed at dealing with gangsterism (cf. National Youth Policy, 2015). Youths' involvement will provide them with recognition and a sense of worthiness, hope for alternatives to gang membership, skills to assist them to become resilient, and opportunities to observe and engage in alternative life styles. In addition, it is important that the socio-economic challenges in this area should receive focused attention from politicians, government structures and non-governmental organisations, who must work as partners to support positive change. The findings in this discussion can serve as a guide towards initiating a movement away from a culture of poverty, unemployment, crime, violence and a collective 
sense of powerlessness. Although the authors have emphasised the contextual nature of the discussion of this phenomenon, it is envisaged that the findings and concluding recommendations could also guide services provided to vulnerable youths in other contexts affected by poverty, unemployment, historical injustices and gangs.

\section{Acknowledgements}

This article is based on a research study conducted as part of a research module in the undergraduate programme of the Department of Social Work at the University of the Western Cape (UWC). The authors would like to acknowledge the fourth-year Social Work students of 2016, who conducted the research. The study was led by Dr G. Dykes, who was supported by Dr A. Beytell, Dr S. Carelse, Dr N. Henderson, Dr M. Minnaar-McDonald, Ms F. Brey, Ms R Davids, Ms A. Human and Ms N Lukelelo.

\section{REFERENCES}

ABDEL-KHALEK, A.M. 2017. Introduction to the psychology of self-esteem. Egypt: University of Alexandria: Nova Science Publishers, Inc.

BAYAT, A., LOUW, W. \& RENA, R. 2014. The impact of socio-economic factors on the performance of selected high school learners in the Western Cape Province, South Africa. Journal of Human Ecology, 45(3):183-196. https://doi.org/10.1080/09709274.2014.11906692

BERNSTEIN, A. 2017. No country for young people. The crisis of youth unemployment and what to do about it. Johannesburg: The Centre for Development and Enterprise.

BEYERS, M. 2018. Teacher experiences of learner retention in the foundation phase. Department of Education, University of Pretoria (Doctor of Education thesis)

BLAŽEVIC, I. 2016. Family, peer and school influence on children's social development. World Journal of Education, 6(2):42-49. https://doi.org/10.5430/wje.v6n2p42

BLISS, L.A. 2016. Phenomenological research: Inquiry to understand the meanings of people's experiences. International Journal of Adult Vocational Education and Technology, 7(3):14-25. https://doi.org/10.4018/IJAVET.2016070102

BOWERS DU TOIT, N.F. 2014. Gangsterism on the Cape Flats: A challenge to "engage the powers". HTS Teologiese Studies/Theological Studies, 70(3):1-7. https://doi.org/10.4102/hts.v70i3.2727

BRYMAN, A. 2016. Social research methods. ( $5^{\text {th }}$ ed). Oxford: Oxford University Press.

CHOE, D. A., ZIMMERMAN, M.A. \& DEVNARAIN, B. 2012. Youth violence in South Africa: Exposure, attitudes, and resilience in Zulu adolescents. Violence and Victims, 27(2):166-181. https://psycnet.apa.org/doi/10.1891/0886-6708.27.2.166

COLLINS, A. 2013. Violence is not a crime: The impact of 'acceptable' violence on South African society. South African Crime Quarterly, 43:29-37. https://doi.org/10.17159/24133108/2013/v0i43a825

COOPER, A. \& WARD, C.L. 2012. Intervening with youths in gangs. In: WARD, C.L., VAN DER MERWE, A. \& DAWES, A. Youth violence: Sources and solutions in South Africa. Cape Town: UCT Press: 241-274.

CRESWELL, J.W. 2009. Research design: qualitative, quantitative, and mixed methods approaches. ( $3^{\text {rd }}$ ed). Los Angeles: SAGE Publications Inc.

DAVIDS, T. 2019. A qualitative assessment on the impact of the youth development programme of the Chrysalis Academy in Cape Town on the lives of past participants. Department of Social Development, Faculty of Humanities; University of Cape Town (Master of Social Development thesis) 
DAVIDS, O., LONDT, M. \& WILSON, L. 2015. Imprisoned sex offenders' chronic denial and their childhood family environment. The Open Family Studies Journal, 7(1):42-47. https://doi.org/10.2174/1874922401507010042

DEPARTMENT FOR WOMEN, CHILDREN AND PEOPLE WITH DISABILITIES. 2012. National Plan of Action for children in South Africa. 2012-2017. Pretoria: Department for Women, Children and People with Disabilities.

DEPARTMENT OF SOCIAL DEVELOPMENT. 2012. Country assessment on youth violence, policy and programmes in South Africa. Pretoria: Department of Social Development and the World Bank.

DE LANNOY, A. 2018. Unpacking the lived realities of Western Cape youth: Exploring the wellbeing of young people residing in five of the most deprived areas in the Western Cape Province. Cape Town: University of Cape Town.

DEVLIN, A. S. 2018. The research experience: Planning, conducting and reporting research. Thousand Oaks: SAGE Publications Inc.

DE WET, C. 2016. The Cape Times's portrayal of school violence. South African Journal of Education, 36(2):1-12. https://doi.org/10.15700/saje.v36n2a1231

FW DE KLERK FOUNDATION. 2019. Is Militarising policing in the Western Cape the answer? [Online] Available: https://www.fwdeklerk.org/index.php/en/latest/news/919-article-is-militarisingpolicing-in-the-western-cape-the-answer [Accessed 2019/11/18].

GEORGE, G.S., FERGUSON, L.A. \& PEARCE, P.F. 2014. Finding a needle in the haystack: Performing an in-depth literature search to answer a clinical question. Nursing Research and Reviews, 4:65-76. https://doi.org/10.2147/NRR.S63578

GOULD, C. \& WARD, C.L. 2015. Positive parenting in South Africa: Why supporting families is key to development and violence prevention. Policy brief 77. Pretoria: Institute for Security Studies.

GROTKAMP, S.L., CIBIS, W.M., NÜCHTERN, E.A., VON MITTELSTAEDT, G. \& SEGER, W.K. 2012. Personal factors in the international classification of functioning, disability and health: prospective evidence. The Australian Journal of Rehabilitation Counselling, 18(1):1-24. [Online] Available: https://pdfs.semanticscholar.org/92fe/b5738b4c5ba114b6ef718cfe46dd470e2167.pdf [Accessed 2020/06/05].

HEAD, T. 2020. Child killed in Ocean View: Angry locals attack gangsters, burn down 'drug house'. [Online] Available: https://www.thesouthafrican.com/news/emaan-solomons-murder-oceanview-protests-vigilante-updates/ [Accessed 2020/02/28].

JAIN, V., SHARMA, R. AND SINGH, S. 2012. Doing meta-analysis in research: A systematic approach. Indian Journal of Dermatology, Venereology, and Leprology, 78(3):242-250. https://doi.org/10.4103/0378-6323.95438

JOHNSON, A. P. 2014. Education psychology: Theories of learning and human development. El Cajon, CA: National Social Science Press.

KAHN, G. 2013. Exploring adolescents' perceptions of the influence of substance abuse on community violence within a Cape Flats community. Department of Psychology, University of the Western Cape (Masters of Psychology thesis)

KESSON, C., MORGAN, G. \& GREEN, C. 2019. Resilient Cape Town: Preliminary resilience assessment. Cape Town: Committee on Sustainability and Resilience, City of Cape Town.

KINNES, I. 2017. Contested governance: Police and gang interactions. Department of Public Law. Faculty of Law, University of Cape Town ( $\mathrm{PhD}$ in Criminology thesis) 
KOOPMAN, O. 2015. Phenomenology as a potential methodology for subjective knowing in science education research. Indo-Pacific Journal of Phenomenology, 15(1):1-10. https://doi.org/10.1080/20797222.2015.1049898

LACHMAN, J.M., SHERR, L.T., CLUVER, L., WARD, C.L., HUTCHINGS, J. \& GARDNER, F. 2016. Integrating evidence and context to develop a parenting program for low-income families in South Africa. Journal of Child and Family Studies, 25(7):2337-2352. doi 10.1007/s10826-016-0389-6

LAPAN, S.D., QUARTAROLI, M.T. \& RIEMER, F.J. (eds). 2012. Qualitative research: An introduction to methods and designs. San Francisco, CA: Jossey-Bass.

LE MAGIDI, T. 2018. Fear as gang violence on Cape Flats escalates. [Online] Available: https://www.iol.co.za/weekend-argus/news/fear-as-gang-violence-on-cape-flats-escalates-18638560 [Accesses 2019/11/16].

MAGIDI, M., SCHENK, R. \& ERASMUS, C. 2016. High school learners' experiences of gangsterism in Hanover Park. The Social Work Practitioner-Researcher, 28(1):69-84. [Online] Available: http://hdl.handle.net/10520/EJC194911 [Accessed 2020/06/05].

MOKSNES, U.K. \& REIDUNSDATTER, R.J. 2019. Self-esteem and mental health in adolescents-level and stability during a school year. Norsk Epidemiologi, 28(1-2):5967. https://doi.org/10.5324/nje.v28i1-2.3052

NATIONAL YOUTH POLICY 2015 - 2020. 2015. We are generation 2020. We don't want a handout, we want a hand up! Office of the Presidency, Republic of South Africa.

ORTH, U. \& ROBINS, R.W. 2013. Understanding the link between low self-esteem and depression. $\begin{array}{llll}\text { Current Directions in } & \text { Psychological }\end{array}$ https://doi.org/10.1177\%2F0963721413492763

PEPPLER, K. (ed). 2017. The SAGE encyclopaedia of out-of-school learning. Thousand Oaks: Sage Publications Inc.

PETER, M.Z., PETER, P.F.J. \& CATAPAN, A.H. 2015. Belonging: Concept, meaning, and commitment. US-China Education Review, 5(2):95-101. doi: 10.17265/2161-6248/2015.02.003

PETERSEN, T. 2020. Pregnant woman shot dead in her Cape Town home. [Online] Available: https://www.news24.com/SouthAfrica/News/pregnant-woman-shot-dead-in-her-cape-town-home20200227 [Accessed 2020/02/28].

PETRUS, T. \& KINNES, I. 2019. New social bandits? A comparative analysis of gangsterism in the Western and Eastern Cape provinces of South Africa. Criminology \& Criminal Justice, 19(2):179-196. https://doi.org/10.1177\%2F1748895817750436

PILLAY, J. 2016. Problematising child-headed households: The need for children's participation in early childhood interventions. South African Journal of Childhood Education, 6(1):1-10. http://dx.doi.org/10.4102/sajce.v6i1.359

PINNOCK, D. 2019. Cape Town's bloody gang violence is inextricably bound up in its history. [Online] Available: https://mg.co.za/article/2019-08-10-00-cape-towns-bloody-gang-violence-is-inextricablybound-up-in-its-history [Accessed 2019/11/16].

RICH, E.G. \& ROMAN, N.V. 2019. Legislative policies and culture on parenting practices: Improving the parent-child relationship in South Africa. Revista de Políticas Públicas, 23(1):389-401. http://dx.doi.org/10.18764/2178-2865.v23n1p389-401

RITCHIE, J., LEWIS, J., NICHOLLS, C.M. \& ORMSTON, R. 2014. Qualitative research practice: A guide for social science students and researchers. ( $2^{\text {nd }}$ ed). London: SAGE Publications Inc. 
RODRIGO, M.J., BYRNE, S. \& RODRÍGUEZ, B. 2013. Handbook of child well-being: Theories, methods and policies in global perspective. Dordrecht: Springer Science and Business Media.

SAULS, H. 2014. A situational analysis of youth in the Western Cape. Ref. No. 12/1/2/3/17. Cape Town: Directorate Research, Population and Knowledge Management; Western Cape Department of Social Development.

SHERR, L., MACEDO, A., CLUVER, L.D., MEINCK, F., SKEEN, S., HENSELS, I.S. \& TOMLINSON, M. 2017. Parenting, the other oldest profession in the world-a cross-sectional study of parenting and child outcomes in South Africa and Malawi. Health Psychology and Behavioural Medicine, 5(1):145-165. https://dx.doi.org/10.1080\%2F21642850.2016.1276459

SCHURINK, C.B.; FOUCHÉ, C.B. \& DE VOS, A.S. 2011. Qualitative data analysis and interpretation. In: DE VOS, A.S., STRYDOM, H., FOUCHé, C.B. \& DELPORT, C.S.L. (eds). Research at grass roots for the social sciences and human service professions. (4 ${ }^{\text {th }}$ ed). Pretoria: Van Schaik: 397-430.

SOUTH AFRICAN POLICE SERVICE. 2019. South African Police Service Annual Report 2018/2019. Pretoria: Strategic Management; South African Police Service.

STATISTICS, SOUTH AFRICA. 2019. Quarterly labour force survey, $\mathbf{2}^{\text {nd }}$ quarter. Pretoria: Statistics South Africa.

TRIPATHY, J. P. 2013. Secondary data analysis: Ethical issues and challenges. Iranian Journal of Public Health, 42(12):1478-1479. ISSN: 0304-4556.

VAN DER LINDE, D.C. 2018. Criminal gang activities: A critical and comparative analysis of the statutory framework under South African criminal law. Faculty of Law University of Stellenbosch (Doctor of Law thesis)

VAN DER MERWE, A., DAWES, A. \& WARD, C.L. 2012. The development of youth violence: An ecological understanding. In: WARD, C.L., VAN DER MERWE, A. \& DAWES, A. Youth violence: Sources and solutions in South Africa. Cape Town: UCT Press: 53-92.

VAN DER WESTHUIZEN, M. 2015. Relapse prevention for chemically addicted adolescents in recovery: so which model works? Journal of Evidence Informed Social Work: 12(4):1-12. https://doi.org/10.1080/15433714.2013.858089

WARD, C.L., VAN DER MERWE, A. \& DAWES, A. 2012. Youth violence: Sources and solutions in South Africa. Cape Town: UCT Press.

WARNICK, D., VAN DER WESTHUIZEN, M. \& ALPASLAN, N. 2019. Falling through the cracks: Young adults' recollections of exposure to domestic violence during childhood. Social Work/Maatskaplike Werk, 55(4):406-423. https://doi.org/10.15270/55-4-760

WESTERN CAPE DEPARTMENT OF SOCIAL DEVELOPMENT. 2013. Western Cape Youth Development Strategy. Cape Town: Department of Social Development, Western Cape.

WESTERN CAPE DEPARTMENT OF COMMUNITY SAFETY. 2018. Provincial policing needs and priorities (PNP) Report for the Western Cape 2018/19 on the policing of drugs. Cape Town: Directorate: Policy and Research; Western Cape Department of Community Safety.

WIJNBERG, M. 2012. Exploration of male gang members' perspectives of gangs and drugs. Department of Social Work, University of Stellenbosch (Master of Social Work thesis) 